\title{
PROTECTIVE FOOTWEAR AND THE RISK OF SLIPPING IN OLDER WORKERS - DEFINITIONS, ACHIEVEMENTS, RECOMMENDATIONS
}

\author{
Emilia Irzmańska \\ Central Institute for Labour Protection-National Research Institute \\ Author's address: Department of Personal Protective Equipment, ul. Wierzbowa 48, 90-133 Łódź, \\ e-mail: emirz@ciop.lodz.pl
}

\begin{abstract}
:
Foot slippage is the most widespread unforeseen event causing falls on the same level, and a potentially contributing factor to falls from height and falls to a lower level. Statistical data on the number of slip-related accidents at work show the importance of the problem of slipping and indicate the need to continuously improve preventive measures designed to reduce injuries related to slipping, tripping, and falling (STF) on the same level. It is therefore necessary to continuously and insightfully analyze the causes of falls and undertake efforts to eliminate the occurrence of slipand trip-induced workplace accidents. The occurrence of slips and trips is primarily related to the type and quality of floor surfaces, but it also depends on the biomechanical characteristics of the lower limbs in the transitional phases of walking gait, sole material and tread, human factors such as age, weight, and motor and vision function, the ability to adapt to the floor surface conditions, as well as on a number of factors linked to the workplace environment and work organization. This problem is going to escalate as a result of the higher retirement age, due to which many persons over the age of 60 will have to continue working, often in hazardous conditions.
\end{abstract}

\section{Keywords:}

slip, fall, older workers, tripp

\section{Introduction}

Foot slippage is the most widespread unforeseen event causing falls on the same level, and a potentially contributing factor to falls from height and falls from a lower level. Grönqvist [17] defines slipping as 'a sudden loss of grip, often in the presence of liquid or solid contaminants and resulting in sliding of the foot on a surface due to a lower coefficient of friction than that required for the momentary activity.' Additionally, some other external and internal factors may also contribute to injuries; these include inadequate lighting, poor housekeeping, ageing, vestibular disease, peripheral neuromuscular dysfunction, diabetes, osteoporosis, alcohol consumption, and the use of anxiolytic drugs. Manning et al. [28, 29] use the term 'underfoot accident' to describe fall-related injuries and other adverse effects initiated by an unexpected interaction between the victim's foot and the floor surface. This definition also includes unforeseen events other than slipping, such as tripping, stumbling, missed footing, twisted foot or ankle, treading on air (at the margin of a surface), and collapsed or moved surface.

Statistical data on the number of slip-related accidents at work show the importance of the problem of slipping and indicate the need to continuously improve preventive measures designed to reduce injuries related to slipping, tripping, and falling (STF) on the same level. The contributing factors include: material defects, construction defects, or inadequate technical or ergonomic design of the material factors. Among the risk factors identified for slipping are inadequate and ill-fitting footwear, worn-out footwear, footwear with excessively high heels, and slippery footwear. Therefore, in most workplaces, the selection of adequate footwear is a critical issue in preventing STF events. The health protection of workers exposed to the risk of slip-related falls requires, along with collective protection measures and organisational solutions, appropriate personal protective equipment with protective and functional parameters verified by laboratory tests and with good ergonomic characteristics (ergonomic design should also take into consideration involution processes). It should be stressed that physical fitness and motor coordination decline with age, which may increase the risk of slip-related falls. Furthermore, this problem is going to escalate as a result of the higher retirement age, due to which many persons over the age of 60 will have to continue working, often in hazardous conditions. Statistical data from the years 2003-2012 show an increase in employment of people aged 20-65 years from 57.3 to $64.7 \%$. Employment of older people in the same years also increased from 27.1 to $38.7 \%$ [8]. According to forecasts, by 2020 , the proportion of people working after age 60 is expected to increase by $22.4 \%$ [9]. Importantly, in older persons, involution processes lead to a limited range of motion, reduce the strength of the lower limbs by up to $40 \%$ [23], and impaired muscle tone and balance, significantly elevating susceptibility to slipping and falling [46]. The environmental factors predisposing older persons to fall events include uncomfortable, ill-fitting, and slippery footwear [1, 2, 21, 47]. Pursuant to EU law, footwear classified as personal protective equipment is subjected to detailed laboratory evaluation, including slip resistance. According to the standards currently applicable to footwear assessment in terms of compliance with Directive 89/686/ EEC [13], slip resistance is a basic requirement for all types of protective footwear. 


\section{Locomotor biomechanics in older adults}

With age, one's range of motion, muscle elasticity, and physical fitness become increasingly limited. Older persons tend to walk more slowly and with a shorter stride length, and land flatfooted. Lower mechanical work expenditure (MWE) of the hips is observed in the frontal plane (circumduction and abduction) in the initial phase of the gait cycle, while higher MWE is observed in the sagittal plane (flexion and extension) in the final phase of the gait cycle. Changes in gait are attributable to compensation for age-related mobility limitations and lead to an increased risk of falling [45].

Another age-associated condition affecting locomotor biomechanics is limited joint mobility, which may affect normal human gait and make older adults vulnerable to slip and fall events. The factors determining joint mobility include not only muscles, but also articular cartilage, articular capsules, and ligaments. Muscles lose their elasticity with age, which affects the ability to flex joints. Table 1 presents average active ranges of motion for selected joints in three planes for persons in three age groups: $18-40$ years, $41-60$ years, and 61-85 years [5]. As can be seen from the table, in 61-85-year-olds, the active mobility of joints may be reduced by up to $23 \%$ compared to young age.

Table 1: Changes in the range of motion (joint flexion angle) with ageing [5]

\begin{tabular}{|c|c|c|c|}
\hline \multirow{4}{*}{ Joint } & \multicolumn{3}{|c|}{ Sagittal plane (flexion) } \\
\cline { 2 - 4 } & $18-40 \mathrm{yr}$ & $41-60 \mathrm{yr}$ & $61-85 \mathrm{yr}$ \\
\hline Hip joint & $125^{\circ}$ & $110^{\circ}$ & $103.25^{\circ}$ \\
\hline Knee joint & $135^{\circ}$ & $125^{\circ}$ & $104^{\circ}$ \\
\hline Ankle joint & $45^{\circ}$ & - & - \\
\hline
\end{tabular}

According to the statistics reported by the Centers for Disease Control and Prevention (CDC), as many as $25 \%$ of injuries leading to hospitalisation are caused by STF events, as shown in Figure 1 [7].

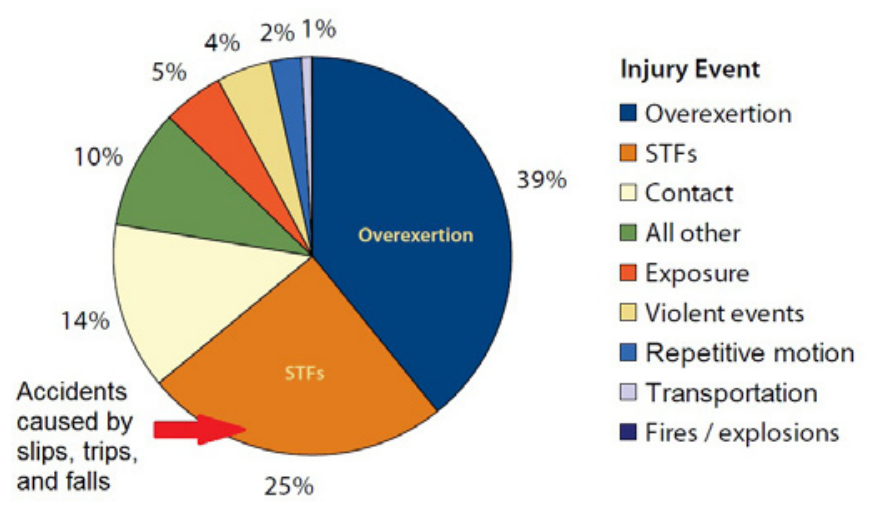

Figure 1: Breakdown of accidents at work by cause, including STF leading to hospitalisation [7]. The segment marked with an arrow corresponds to STFs. STF: Slips, trips, and falls

Unexpected perturbations in gait include forward and backward slips. Different types of slips entail very different levels of risk. A bilateral slip may occur if the non-slipping (trailing) foot is brought to the slipping (leading) foot, leading to a fall with both feet directed forward. Such falls are very dangerous because they result in a greater likelihood of hip and wrist injury. If a shorter step is made to prevent a fall, the trailing foot continues to support the body, but the leading foot moves away in the direction of the slip. This is termed a unilateral slip and in such a case, it is very probable that the feet will remain wide apart. Research has shown that while the type of slip does not affect the probability of a fall, older persons are less likely to experience a bilateral slip. This is probably due to slower walking speeds and shorter stride lengths, which make it easier to prevent bringing the feet close together [38, 48]. The main physiological changes that increase the risk of slipping and falling may begin to appear as early as after the age of 20 , when muscle strength is at its peak. Then, strength gradually declines until age 50, after which it begins to deteriorate rapidly. Research shows that age-related changes in muscle strength significantly affect both slip initiation and recovery. It should be remembered that despite generally lower walking speeds in older adults (e.g., due to shorter stride length), the anteroposterior heel velocity during the phase of moving the centre of mass in older people is higher than that in young individuals [25].

\section{The relationship between slipping and}

\section{footwear outsole friction}

Normal human locomotion depends not only on biophysical function, but also on foot grip on the floor surface, which basically means the friction at the foot-floor interface. Insufficient friction leads to slippage, which makes walking more difficult or entirely impossible.

While friction is widely applied as a measure of slipperiness, there is some controversy concerning the exact nature of the relationship between these two physical phenomena [11]. For instance, the question arises as to what kind of friction (static, dynamic, transitional) should be considered in this context and whether friction as a parameter is adequate for explaining slipping as an event. Furthermore, results may vary depending on the measurement method used. Despite the above limitations, friction measurement is one of the most widespread methods of evaluating slipperiness. Natural surfaces, roads, concrete and asphalt pavements, and wooden and polymer floors are sufficiently rough and, if dry, they usually do not give rise to uncontrolled footwear sliding. In the case of slipping involving dry friction, the outsole elastomer is periodically deformed by the rough surface, while the frictional force is the sum of the adhesion force and energy dissipated due to hysteresis. For both components of frictional force, of profound significance is the true contact area, which depends on the degree of smoothness of the contacting bodies and on the normal force acting on the moving body. Both adhesion and hysteresis are also affected by the contact time of the interacting surfaces, which is in turn affected by the relative speed of moving bodies. In normal walking, the microscopic roughness of the floor surface and elastic footwear soling 
ensure good contact over a relatively large area. With faster walking speed, the area and time of contact with the floor surface decrease, while mechanical losses increase due to greater deformation of the outsole. Thanks to that, slips do not tend to occur on dry surfaces even in the case of a fast walk or run. However, the nature of friction changes if a liquid film or solid suspension intervenes between the sole and floor surface, typically reducing the frictional force (so-called liquid friction occurs). In practice, the layer of liquid (water, lubricant, oil, etc.) found on the surface across which a pedestrian moves is contaminated with sand, gravel, metal shavings, etc. If this is the case, then the soles come into contact alternately with a solid and a liquid, and the process of slipping is governed by the laws of physics applicable to both dry and liquid friction (which is termed mixed friction) [18].

Considerably more research has been devoted to slipping on liquid-contaminated surfaces than on surfaces covered with solid contaminants or ice [11]. According to literature data, when the layer of liquid intervening between the interacting solid surfaces reaches a certain critical thickness, then the coefficient of friction approaches zero [19]. Liquid phase particles become bound to the solid surfaces as a result of physical or, less often, chemical adsorption. In the immediate vicinity of solid bodies, liquids display different properties than bulk liquid. The boundary layer at the solid-liquid interface usually exhibits elevated viscosity and density. The mechanisms governing particulate matter behaviour are still not well understood. Based on experiments, Heshmat et al. [19] hypothesised that in the case of dry contaminants, friction mechanisms may involve rolling, shearing, normal fracture, elasticity, and slip.

While humans often walk on icy surfaces, it is very difficult to examine the friction of polymer materials at below-freezing temperatures due to the constantly changing thermal conditions at the interface between interacting bodies. Bowden and Hughes [6] demonstrated that the very low frictional force between ice and other materials is due to the formation of a thin water layer as a result of friction-induced heating, which is additionally enhanced by the presence of contaminants such as salts, increasing the melting temperature of ice. Furthermore, the higher compression forces acting on the protrusions found on footwear soles and on floor surfaces also, to some degree, promote melting of the ice layer. However, ice as such is not always slippery. The friction coefficient for ice may vary from extremely low $(\mu<0.01)$ at a relatively high temperature $\left(-1^{\circ} \mathrm{C}\right)$ and at high speed $\left(3 \mathrm{~m} \mathrm{~s}^{-1}\right)$ to very high $(\mu=0.67)$ at low temperature $\left(-40^{\circ} \mathrm{C}\right)$ and at low speed $\left(0.001 \mathrm{~m} \mathrm{~s}^{-1}\right)$.

The friction mechanisms in walking were intensively studied by Tisserand, Strandberg, Proctor and Coleman, Grönqvist, and Leclercq et al. [15, 36, 43, 45]. Chang et al. [11] produced a review of research in this area, focusing on friction mechanisms at the footwear-floor interface for dry, liquidcontaminated, solid-contaminated, and ice-covered surfaces. The tribophysical mechanisms linked to slipping incidents involve the ability of the footwear-floor contact area to drain off contaminants (through squeeze film processes), the draping of the shoe sole around the asperities, or protrusions, of the floor surface (related to hysteresis), and the true contact between the interacting surfaces (linked to traction). The squeeze film processes occurring between the footwear and the floor surface immediately following heel strike have a critical effect on walking balance and safety when the interacting surfaces are contaminated. Therefore, one of the key elements in preventing slip and fall injuries is for pavements, pedestrian crossings, flooring materials, and footwear soles to have good drainage capability. This in turn determines how effectively the footwear sole will be pressed against the asperities of the floor surface, enabling deformation and true contact in the presence of contamination. The term 'squeeze film' applies to situations in which two approaching surfaces, such as the footwear heel and the floor surface, displace a viscous liquid from between them under the influence of force [33]. The friction at the footwear-floor interface due to hysteresis and adhesion reflects the same viscoelastic mechanism of energy dissipation. Adhesive friction is caused by the dissipative stick-slip mechanism at the molecular level, while hysteretic friction corresponds to the irreversible and delayed response during an elastic contact stress cycle. Hysteresis arises due to the fact that during a slide across a rigid surface, elastomeric soling does not recover completely to its original shape when the stress is removed. This leads to asymmetrical deformation and pressure distribution across the contact area during the slide. If liquid drainage and elastomer conformation to the floor surface upon heel strike (involving dynamic loading) are too slow as a result of hydrodynamic load support and elastohydrodynamic effects, then frictional forces at the footwear-floor interface will not develop sufficiently to prevent slipping. In the opposite case, if sole conformation (draping) happens fast enough, then adequate frictional forces can develop through deformation and damping (macro- and micro-hysteresis) and true molecular contact (adhesion and wear) between the interacting surfaces. The latter case is obviously far safer. Both the horizontal shearing force $\left(F_{H}\right)$ and the vertical impact force $\left(F_{v}\right)$ exerted by the foot on the surface have an effect on the risk of slipping. In the presence of contaminants such as water or oil, lower impact forces $\left(F_{v}\right)$ usually lead to smaller maximum hydrodynamic pressure in the squeezed film compared to greater impact forces [33]. When film thickness approaches zero, a lower maximum hydrodynamic pressure, which is determined by the footwearfloor contact area and liquid viscosity, results in reduced hydrodynamic load support enabling the development of both hysteretic and adhesive friction at the footwear-floor interface. Therefore, a more gentle heel impact on the floor leads to a lower slip and fall risk. It should be noted that in the case of static loads, for example, in a situation of standing still, maximum pressure in a contaminant film does not depend on film thickness.

\section{The role of footwear in preventing slips and}

\section{falls}

Appropriate footwear is a key factor in maintaining balance and fall prevention. According to research, many persons wear poorly fitting footwear, or footwear that is worn out or 
inappropriate for a given activity, which increases the risk of tripping, slipping, and falling [1]. Both inadequate footwear and the absence of footwear may cause a fall [30]. Despite the fact that footwear dampens the sensory response of the feet in contact with floor surfaces, the risk of falling while walking barefoot or in socks is several times greater than in the case of wearing sports footwear. Furthermore, footwear protects the foot from mechanical injury and ragged surfaces, which in itself may decrease the risk of falling, especially outdoors. However, it has been reported that persons wearing home footwear that does not offer proper support for the stability of a moving human body are exposed to a greater risk of falling than barefoot individuals. In 2012, S. Chen, J. Jin, E. Lou, developed guidelines concerning the selection of anti-slip footwear [12], which included the following points:

- Outsole materials - out of the studied materials, natural rubber provides the best anti-slip properties on dry surfaces, while nitrile butadiene rubber (NBR) and polyurethane (PU) are better suited for surfaces contaminated with liquids, such as water or oil. The least safe footwear, which increases susceptibility to falls, contains outsoles made of polyvinyl chloride (PVC), ethylene vinyl acetate copolymer (EVA), and thermoplastic rubber.

- Outsole hardness - despite the fact that soft outsoles are suboptimal from the point of view of supporting postural stability, they have superior anti-slip properties. This is due to the fact that soft soles are more easily deformable and better conforming to the floor surface, thus increasing friction and contact area.

- Outsole tread - the shapes forming the tread are another major element in the classification of anti-slip footwear. Simple recurrent geometrical patterns (e.g., circles, squares) facilitate the dispersion of contaminants to the outer edges of the outsole, improving footwear grip on the floor.

- Presence of drainage channels - they facilitate the drainage of contaminants (water, oil, mud) to the outer edges of the outsole. The only requirement concerning them is that they should be at least $2 \mathrm{~mm}$ wide and 2-7 $\mathrm{mm}$ deep.

- Comfort and fit - well-fitting and comfortable footwear (e.g., shoes with extra support for the heel) allows maximum gait synchronisation, reducing the risk of slipping and falling.

The above guidelines are extremely important, especially in the context of the research showing that, according to approximately $10 \%$ of the surveyed individuals, footwear with inadequate outsoles contributed to the risk of slipping and falling [2]. A study by C. Gao, I. Holmer, and J. Abeysekera reports that anti-slip properties come second in evaluation of occupational footwear, especially with regard to persons working outdoors in a cold climate [14]. Another important aspect of designing antislip footwear is heel height. Footwear with higher heels shifts the centre of mass of the wearer upward and forward and may lead to changes in posture and movement kinematics. In older people, wearing footwear with heels higher than $2.5 \mathrm{~cm}$ results in increased loading on the forefoot and the risk of developing a bunion. High heels affect walking gait, shorten stride length, and impair stability, especially on uneven surfaces due to the small contact area between the sole and the floor. Of great importance for maintaining balance are insoles, and especially their structure. Well-designed insoles enhance postural stability, as shown by Qu, who studied different types of insoles using a force platform [37]. The studied insoles included:

- cupped insoles made from polyester and urethane sponge, with a smooth surface and the heel edge raised by $15 \mathrm{~mm}$

- textured insoles made from polyester and EVA with circular protrusions spaced about $10 \mathrm{~mm}$ apart

- rigid insoles made from PU and EVA

- soft insoles made from slow-rebound foam sponge

As the results show, cupped insoles with a raised heel improve postural stability, especially in the anteroposterior direction, which may be attributable to the increased somatosensory feedback from the receptors located on the heel. The study did not confirm the hypothesis that insoles with a textured surface improve static postural stability, in contrast to previous findings reported by the authors [38]. A comparison of insoles with different surfaces revealed that soft insoles do not support postural stability, while maintaining such stability entails additional loading on the muscles (which is particularly important in older adults, who experience a decline in muscle mass). Harder insoles make it possible for the feet to assume a more natural position, enhancing postural stability without additional loading of the muscles and joints.

One of the objectives of research into footwear slippage is to develop a technology (an appropriate outsole material with good mechanical properties) for increasing slip resistance. There is no consensus about which coefficient of friction (static coefficient of friction - SCOF or dynamic coefficient of friction - DCOF) should be regarded as the critical parameter describing the interaction between the footwear sole and the floor surface. Some studies suggest that a DCOF in the range of $0.2-0.4$ is safe and not conducive to falls. Other researchers have reported that at DCOF levels below $0.3-0.35$, people may modify their gait to avoid slipping [16]. Therefore, a safe coefficient of friction at the footwear-floor interface is assumed to be approximately 0.4 [34].

The relationship between the type of friction coefficient and slipping was investigated by T. Yamaguchi, T. Umetsu, Y. Ishizuka, K. Kasuga, T. Ito, S. Ishizawa, and K. Hokkirigawa [47]. The studied footwear was equipped with hybrid soles made of alternating segments of rubber with a rough and smooth surface, of varying thickness. According to the study, from the point of view of ensuring user safety both coefficients of friction (static and dynamic) should be high to prevent slip initiation, and if it should occur, to stop it promptly. On the other hand, excessively high coefficients of friction may give rise to a risk of another undesirable incident, that is, tripping. In the modelling study, the hybrid sole consisted of a rubber block with a rough surface $(\mathrm{Ra}=30.4 \mu \mathrm{m})$ flanked by two rubber blocks with smooth surfaces $(\mathrm{Ra}=0.98 \mu \mathrm{m})$ with the ratio of the rough surface area to the whole rubber block surface area being $0 \%, 30 \%, 50 \%, 80 \%$, and $100 \%$. The results showed that the SCOF increased with the area of rough surface from 0.17 for $0 \%$ to about 0.9 for $100 \%$, inversely to the DCOF, which declined from more than 1 for $0 \%$ to as little as 0.2 for $100 \%$. The most favourable parameters for anti-slip footwear (about 0.5 ) were obtained for equal proportions of rough and 
smooth surfaces, which led to the best adhesion of the studied material to the floor surface, as confirmed by tests involving total reflection of light.

In summary, according to the literature guidelines and recommendations concerning the effects of different types of footwear on the risk of slipping and falling, older persons should wear footwear with short heels (less than $2.5 \mathrm{~cm}$ ) to avoid the undesirable impact of high-heeled footwear on maintaining the optimum posture and balance [16, 21, 30, 34, 38, 47].

Additionally, footwear should be equipped with a rigid, but not too thick, outsole for it to adequately support postural balance [21]. The sole should be textured to increase the contact area between the footwear and the floor while enabling the drainage of contaminants such as water, which may otherwise pose a risk of slipping and falling. All the above guidelines were collected by J. C. Menant, J. R. Steele, H. B. Menz, B. J. Munro, and S. R. Lord [30], who developed a model of optimum footwear construction for older adults with the following features:

- supported heel-collar

- low heel height

- bevelled heel

- slip-resistant, appropriately textured sole

- thin and firm midsole

- fastening mechanism

The protective footwear used in many workplaces may also increase the risk of falling if it is inappropriately fitted or has a negative effect on the user's gait. It should be stressed that slips and falls are some of the most widespread causes of workplace accidents. They typically occur due to the floor being contaminated with water or lubricants (e.g., oils). Other factors leading to slips at work include inappropriate sole material, shape, or tread, and user-specific characteristics such as age, weight, mobility, walking gait style, and psychological profile. Slips and falls occur most frequently in the food and foodservice industry, construction industry, health care, transportation, and during road works (especially in wintertime) [20].

Due its construction, protective footwear may be classified into shoes, ankle boots, calf-length boots, knee-length boots, and thigh boots. Additionally, protective footwear may contain elements such as [20]:

- shock-absorbing ankle protectors

- steel, aluminium, or plastic toecaps providing protection against impact and compression

- metatarsal protectors against compression and puncture; also metatarsal covers preventing sand, stones, and splashes from getting inside footwear.

Certain element of protective footwear construction, that is, upper height, heel support, and sole structure may adversely affect the walking pattern of workers [22]. Anti-slip protection involves the use of footwear exhibiting good adhesion to the floor surface thanks to appropriate sole treads (increasing friction at the footwear-floor interface and facilitating drainage of liquids from under the sole to the outer edges). The sole materials most often used in anti-slip applications include PU and some types of rubber.

\section{Instrumental testing of the slip-resistance of footwear}

Evaluation of the slip and fall potential of footwear requires comprehensive instrumental testing of footwear in conjunction with balance and gait testing in older users during basic activities such as walking forward or climbing stairs. To date, evaluation studies of the slip and fall potential of footwear have been conducted on casual footwear. They have involved only instrumental laboratory tests of soles and slipping in accordance to the methods specified in relevant standards.

No methodology for the assessment of protective footwear has been developed in the field of evaluating the risk of slip-induced falls in older workers. Furthermore, no research has been published to date concerning the effects of protective footwear construction on that risk. In the past, the slip resistance of footwear used to be measured by means of an inclined plane. Pursuant to one method, a sole or its fragment was placed on an inclined plane with variable slope in order to determine the angle at which the sample would start to slide down. In another method, a human subject would walk on an inclined plane with variable slope, whose surface has been treated with an agent increasing slipperiness. The subject continued walking until his or her gait became unstable. Currently, the basic indicator used in evaluation of footwear slip resistance is the coefficient of friction. The methodology of testing that coefficient should take into account the specific characteristics of human walking gait and the conditions in which the footwear is to be used. Thus, the environment of intended use needs to be reflected in laboratory modelling.

Static devices measuring the coefficient of friction of footwear pertain to the friction that arises when a sample is moved across a surface. What is measured is the horizontal force needed to pull the sample, which is used to calculate the static coefficient of friction. In turn, dynamic devices measure the dynamic coefficient of friction and they may be used both for dry and contaminated surfaces. Selected devices for measuring the coefficient of friction of footwear and their operating principles are given in Table 2.

There are also some laboratory methods employing combination devices that enable evaluation of the friction coefficient and slip for whole footwear rather than for outsole samples. These methods are described in Table 3.

\section{Recommendations for anti-slip protective footwear}

The footwear worn by workers should ensure protection against hazards and be suitable for a given work type and environment. Where necessary, specific footwear should be explicitly recommended as a preventive measure in risk assessment documents. 
Table 2: Selected devices for measuring the coefficient of friction of footwear and their operating principles [3, 10, 39, 41, 42]

\begin{tabular}{|c|c|}
\hline Device & Operating principle \\
\hline \multicolumn{2}{|r|}{ Static devices } \\
\hline HPS & $\begin{array}{l}\text { The footwear sample is pressed to the floor surface with a contact pressure of about } 70.2 \mathrm{kPa} \\
\text { and pulled by the device (the drag force is applied by means of a motor). This device is } \\
\text { appropriate for measuring the coefficient of friction (COF) on dry surfaces only. }\end{array}$ \\
\hline HDPM & $\begin{array}{l}\text { The footwear sample is also pulled across a surface, with a contact pressure of } 38.3 \mathrm{kPa} \text {. Similar } \\
\text { to the HPS, the HDPM measures the horizontal force applied to pull the sample material. Both } \\
\text { dry and wet surfaces may be tested. }\end{array}$ \\
\hline PAST & $\begin{array}{l}\text { The device is an articulated strut slipmeter. The coefficient of friction is calculated from the } \\
\text { tangent of the angle between the strut and the vertical member at which a drastic slip occurs at } \\
\text { the interface between the footwear sample and the floor surface. The contact pressure is about } \\
9.2 \mathrm{kPa} \text {. This method is appropriate for dry surfaces only. }\end{array}$ \\
\hline \multicolumn{2}{|r|}{ Dynamic devices } \\
\hline PFT & $\begin{array}{l}\text { The device is pushed along the floor surface by an operator. The slip necessary for dynamic } \\
\text { measurement occurs between the front wheel, which is braked, and the floor surface. The normal } \\
\text { force acting on the wheel is } 112 \mathrm{~N} \text {. }\end{array}$ \\
\hline Low velocity skidmeter & $\begin{array}{l}\text { The footwear sample is dragged across the floor surface at a speed of about } 0.83 \mathrm{~m} / \mathrm{s} \text {. At the } \\
\text { same time, normal force is applied to the sample using a carriage moving along a rail. }\end{array}$ \\
\hline Tortus & $\begin{array}{l}\text { The device consists of a four-wheel carriage moved across the floor surface. The footwear } \\
\text { sample is mounted on a shaft located near the centre of mass of the carriage. The sample can } \\
\text { move vertically, thanks to which the device can be used for uneven floor surfaces. }\end{array}$ \\
\hline FSC & $\begin{array}{l}\text { The operating principle of this device is similar to the Tortus. The difference is that the footwear } \\
\text { sample may be lowered during the measurement to apply impact loading in order to measure } \\
\text { transitional friction. }\end{array}$ \\
\hline $\begin{array}{l}\text { Gleit MessGerät (GMG } \\
100)\end{array}$ & $\begin{array}{l}\text { The device drags itself along the floor surface using a steel cable anchored to a foot plate. It is } \\
\text { driven by an electric motor and its motion is stabilized by an internal fly wheel to make sure that } \\
\text { the device moves across surfaces in a smooth and stable manner. }\end{array}$ \\
\hline Schuster & $\begin{array}{l}\text { The device is pulled by the operator on the floor surface to measure the coefficient of friction. } \\
\text { Four thin elastomer samples are used to measure the surface properties. }\end{array}$ \\
\hline \multicolumn{2}{|r|}{ Devices measuring transitional friction } \\
\hline $\begin{array}{l}\text { PIAST - Brungraber } \\
\text { Mark II }\end{array}$ & $\begin{array}{c}\text { The device is a gravity-driven inclined strut slipmeter. The footwear sample impacts the floor } \\
\text { surface with a given force and momentum at an angle inclined from the vertical direction. The } \\
\text { coefficient of friction is calculated from the angle at which non-slip motion transitions to slip } \\
\text { motion. }\end{array}$ \\
\hline VIT & $\begin{array}{l}\text { The device is a pneumatic-driven inclined strut slipmeter. Its operating principle is similar to that } \\
\text { of the PIAST device. }\end{array}$ \\
\hline
\end{tabular}

HPS: Horizontal pull slipmeter; HDPM: Horizontal dynamometer pull-meter; PAST: Portable articulated strut tribometer; PFT: Portable friction tester; FSC: Floor slide control; PIAST: Portable inclineable articulated strut tribometer; VIT: Variable incidence tribometer.

Work footwear should be characterised by:

- slip-resistant sole material

- appropriate sole tread pattern

- bevelled heels with a large contact area (high heels with a small contact area should be avoided)

- shock-absorbing sole

- adjustment for involution processes, but without compromising comfort of use

Slip resistance is evaluated for new footwear by measuring the dynamic coefficient of friction at the footwear-floor interface.
The factors influencing the DCOF include the type and tread of the sole, sole and/or floor contamination (e.g., with water, oil, ice), type of floor surface, rigidity or stability of the footwear upper, as well as the wear, roughness, and hardness of the sole and floor surface. The main elements determining the slip resistance of footwear are:

\section{- Footwear construction}

According to scientific research, high heels tend to impair balance in older women [26], while footwear equipped with thick and soft soles hinders balance in older men [40]. 
Table 3: Laboratory methods for testing footwear using combination devices [10]

\begin{tabular}{|c|c|}
\hline Device & Operating principle \\
\hline LABIRNS & $\begin{array}{l}\text { The device measures both static and dynamic friction coefficients of footwear (sole material) and floor } \\
\text { surfaces. Footwear is tested against a stainless steel surface, while floor surfaces are tested using } \\
\text { a flattened footwear model consisting of two pieces of smooth elastomer, which is able to withstand } \\
\text { loads of up to } 600 \text { N. During tests, the floor surface travels at variable speed. The DCOF is measured } \\
\text { at maximum speed (approximately } 0.2 \mathrm{~m} / \mathrm{s} \text { ). }\end{array}$ \\
\hline James Machine & $\begin{array}{l}\text { The operating principle of this device is based on resolution of forces in an inclined strut. The tested } \\
\text { element is mounted on a shaft that can move in the vertical direction only. At the beginning of the test, } \\
\text { the table moves at a constant speed, and its angle from the vertical axis gradually increases. } \\
\text { A slip at the footwear-floor interface occurs before the vertical shaft reaches the bottommost position. } \\
\text { The movements of both the vertical shaft and the table are recorded. The coefficient of friction is } \\
\text { calculated from the angle between the strut and the vertical member at which a drastic slip occurs at } \\
\text { the footwear-floor interface. }\end{array}$ \\
\hline PRST & $\begin{array}{l}\text { The device measures the DCOF at the footwear-floor interface. Measurement involves three } \\
\text { movements of the footwear. Initially, the footwear is lowered vertically onto the floor surface and } \\
\text { fully loaded with a normal force of } 40-80 \mathrm{~N} \text {. After } 0.5 \mathrm{~s} \text {, the tested material is moved across the floor } \\
\text { surface for } 5 \mathrm{~s} \text { (horizontally or at an inclination of } 5-15^{\circ} \text { ). The footwear sliding rate is } 0.01-0.2 \mathrm{~m} / \mathrm{s} \text {. }\end{array}$ \\
\hline Stevenson Device & $\begin{array}{l}\text { In this testing method, the footwear is mounted on a pendulum, with normal force applied by means } \\
\text { of a small hydraulic cylinder. A floor surface sample is attached to an instrument that measures both } \\
\text { frictional force and normal force. The footwear is driven forward by a horizontal cylinder in such a } \\
\text { way that the heel edge makes contact with the floor surface (the footwear is additionally loaded with } \\
\text { normal force). The angle between the footwear and the floor surface is about } 10^{\circ} \text {, and the normal } \\
\text { force applied to the footwear is about } 350 \mathrm{~N} \text {. The footwear travels across the floor at a speed of about } \\
0.4-0.6 \mathrm{~m} / \mathrm{s} \text {. The DCOF is calculated based on the middle segment of the recorded trace. }\end{array}$ \\
\hline $\begin{array}{c}\text { STM } 603 \\
\text { Slip resistance } \\
\text { tester }\end{array}$ & $\begin{array}{l}\text { This machine simulates slipping after heel strike or before toe-off. The footwear is lowered onto the } \\
\text { floor surface at a variable angle of up to } 30^{\circ} \text {. Normal forces of up to } 750 \mathrm{~N} \text { are applied by means of an } \\
\text { air cylinder. After a delay of a few seconds }(0-5 \mathrm{~s}) \text {, a motor pulls the floor surface at a constant speed } \\
\text { of } 1.5-50 \mathrm{~cm} / \mathrm{s} \text {. The load cells attached to the footwear measure the drag force at the footwear-floor } \\
\text { interface. Measurement of the DCOF is made } 0.3 \mathrm{~s} \text { after the initiation of surface movement. }\end{array}$ \\
\hline $\begin{array}{l}\text { TNO step } \\
\text { simulator }\end{array}$ & $\begin{array}{l}\text { This is a computer-controlled simulator. Whole footwear is moved across a stationary floor surface. } \\
\text { The DCOF is calculated from the normal force applied to the mechanism (usually } 350-750 \mathrm{~N} \text { ) and the } \\
\text { transverse shear force necessary to move the heel or sole relative to the floor surface. The footwear } \\
\text { can contact the floor surface at angles from } 0^{\circ} \text { to } 10^{\circ} \text {. The sliding rate ranges from } 0.1 \text { to } 0.4 \mathrm{~m} / \mathrm{s} \text {. }\end{array}$ \\
\hline Slip simulator & $\begin{array}{l}\text { The device simulates a slip following heel strike in normal walking. The footwear is mounted on an } \\
\text { artificial foot and moved by means of three hydraulically powered cylinders. The horizontal cylinder } \\
\text { initiates movement slightly above the floor surface at a constant speed (about } 0.4 \mathrm{~m} / \mathrm{s} \text { ), while the } \\
\text { vertical cylinder lowers the foot onto the floor surface (at about } 0.1 \mathrm{~m} / \mathrm{s} \text { ). The inclination cylinder } \\
\text { positions the footwear heel at a selected footwear-floor contact angle. Frictional and normal forces } \\
\text { at the footwear-floor interface are measured using a force platform. In most tests, the normal force } \\
\text { applied to the footwear is about } 700 \mathrm{~N} \text {, while the sliding speed is about } 0.4 \mathrm{~m} / \mathrm{s} \text {. The angle between } \\
\text { the footwear and floor surface is typically } 5^{\circ} \text {. }\end{array}$ \\
\hline $\begin{array}{l}\text { Boden und } \\
\text { Schuhtester } \\
\text { Device } 2000 \text { (BST } \\
\text { 2000) }\end{array}$ & $\begin{array}{l}\text { The device consists of a frame with drive units for a table, powered by an electric motor, a } \\
\text { superstructure for the tested footwear, and a force-measuring element. The table travel rate is } \\
\text { sinusoidally variable with a maximum at } 0.5 \mathrm{~m} / \mathrm{s} \text {. The measurement procedure is repeated } 5 \text { times to } \\
\text { obtain an average from individual steps. The footwear may be mounted at an angle of } 15^{\circ} \text { relative to } \\
\text { the floor surface (it may also be rotated by } 360^{\circ} \text { ). The normal force applied may be varied in the range } \\
\text { of } 0-750 \mathrm{~N} \text { (with a typical level of about } 500 \mathrm{~N} \text { ). The DCOF is evaluated at a speed of } 0.2 \mathrm{~m} / \mathrm{s} \text { at the } \\
\text { onset of slide. }\end{array}$ \\
\hline
\end{tabular}

LABIRNS: French National Research and Safety Institute Laboratory Device; PRST: Programmable slip resistance tester.

Footwear with high collars is preferable over footwear with low collars from the point of view of balance in persons 60 years of age and older [27]. A stable human heel position within footwear is another critical factor preventing slips [31]. A strong relationship between stability and footwear collar height in persons aged $60+$ has also been reported [32].

\section{- Sole material}

Rubber soles have long been praised for their slip resistance and good friction properties. However, there is no consensus as to which sole material best prevents slipping. Experiments conducted by different researches have shown that during slip tests polyurethane soles undergo considerable wear and 
degradation due to sole softness. Nitrile rubber soles perform better than polyurethane soles on clean and dry surfaces. On the other hand, the slip resistance of PVC soles gradually increases upon artificial attrition, which makes the sole topography rougher. Given the huge variety of situations that may occur in the workplace, it is impossible to identify one type of footwear that will ensure maximum slip and fall prevention in all situations.

\section{- Sole tread}

An appropriate sole tread is of key importance for ensuring slip resistance on wet surfaces. Sole tread disrupts liquid films and drains liquid contaminants away, due to which the interface between the raised parts of the sole tread (cleats) and the floor surface exhibits nearly dry conditions. It is believed that numerous small cleats provide better anti-slip properties than few large cleats. Tread patterns should be open to the sides for dirt and liquids to be removed as a result of natural sole bending in the process of walking. Cleats should be smooth and flat to ensure maximum contact area between the sole and floor.

\section{- Heel style}

It has been found that $90 \%$ of fall-inducing slips are initiated at the place where the heel strikes the floor. In the workplace, the coefficient of friction of the heel affects grip, efficiency, and safety. Slip resistance may be improved by fine tread patterns on heels, which should be perpendicular to the longitudinal axis of the sole. Furthermore, the greater the heel bevel angle, the greater the contact area upon heel strike, increasing the coefficient of friction.

\section{- Hardness}

Generally speaking, the harder the material, the greater the likelihood of slipping, but under some circumstances very soft materials may behave unfavourably on wet smooth surfaces. Softer outsoles lead to higher coefficients of friction because floor surface roughness (asperities) results in greater contact area between the footwear and the floor. Footwear with soft soles, for example, made of rubber, is recommended for smooth steel surfaces, both dry and wet, because such soles are deformable and ensure maximum conformation to the floor surface. Footwear with harder soles exhibits better anti-slip properties on rough surfaces, such as concrete. Under wet conditions, footwear with soft soles is preferable.

\section{- Sole wear during footwear use}

It has been estimated that after nearly 4 months of use, slip resistance begins to decline as worn footwear is more likely to slip. Sole wear is affected by factors specific to the workplace in which the footwear is used.

The occurrence of slips and falls is primarily determined by the type and quality of the floor surface, environmental factors, work organisation, biomechanical characteristics of the limbs, footwear construction, sole material and tread pattern, as well as such critical human factors as age and the related mobility issues. Therefore, it is necessary to undertake all efforts to eliminate or reduce the occurrence of slips and falls, which constitute a major category of workplace accidents among older workers.

\section{Summary}

Slips, trips, and falls are some of the most widespread causes of accidents among workers in all sectors, and especially in the food and foodservice industry, construction industry, health care, and transportation. In EU member states, STFs are the main cause of accidents leading to absence from work lasting more than three days. Falls on the same level are not only important occupational safety problems, but they also entail considerable economic and social losses. It is therefore necessary to continuously and insightfully analyse the causes of falls and undertake efforts to eliminate the occurrence of slip- and trip-induced workplace accidents. The occurrence of slips and trips is primarily related to the type and quality of floor surfaces, but it also depends on the biomechanical characteristics of the lower limbs in the transitional phases of walking gait, sole material and tread, human factors such as age, weight, and motor and vision function, the ability to adapt to the floor surface conditions, as well as on a number of factors linked to the workplace environment and work organisation. Slips and falls are often attributable to a variety of concurrently acting causes. Thus, the multiplicity and complexity of external, internal, and mixed risk factors for slipping and falling require a comprehensive approach to this problem, taking into consideration biomechanical, tribological, neurophysiological, and psychological aspects, as well as work organisation.

As far as older workers are concerned, the identification of risk factors for slipping constitutes a very important element or risk management with a view to preventing workplace accidents. Checklists adjusted to the specific conditions of individual workplaces may prove a useful tool for the identification and evaluation of such risks. The methods of measuring surface slipperiness used to date have considerably improved the understanding the mechanisms of slipping and falling and contributed to the development of accident prevention procedures. The most widespread, and probably the oldest, methods of evaluation surface slipperiness involve friction measurement. However, it should be borne in mind that slipperiness and slip are complicated phenomena involving various aspects of biomechanics, tribology, neurophysiology, and human cognitive abilities. In the case of older persons, subjective or human-centred evaluation of footwear and floor surface roughness as well as biomechanical measurements may provide an alternative and a new research direction in friction measurement, or may complement tribological research.

\section{ACKNOWLEDGEMENTS}

The publication is based on the results of Phase III of the National Programme 'Safety and working conditions improvement,' financed in the years 2014-2016 in the area of 
tasks related to services for the State by the Ministry of Labour and Social Policy. The Programme coordinator is the Central Institute for Labour Protection-National Research Institute.

\section{References}

[1] Barton C. J., Bonanno D., Menz H. B. (2009). Development and evaluation of a tool for the assessment of footwear characteristics. Journal of Foot and Ankle Research, 2(10), 1-12

[2] Berg W.P., Alessio H. M., Mills E.M., Tong C. (1997). Circumstances and consequences of falls in independent community-dwelling older adults, Age Ageing, 26(4),261268

[3] Bergstrom A., Astrom H., Magnusson R. (2003). Friction measurement on cycleways using a portable friction tester. Journal of Cold Regions Engineering, 17(1), 37-57

[4] Błaszczyk JW., Czerwosz L. (2005) Stabilność posturalna w procesie starzenia. Gentrologia Polska, 13(1), 25-36

[5] Bober T., Zawadzki J. (2003) Biomechanika układu ruchu człowieka. (2 ed). Wydawnictwo BK (Wrocław)

[6] Bowden F., Hughes T. (1995). The mechanism of sliding friction on ice and snow. Proceedings of the Royal Society of London, Series A,172, 280-297

[7] CDC (2011). Slip, Trip and Fall Prevention for Healthcare workers. Retrieved 11.5.2014. http://www.cdc.gov/niosh/ docs/2011-123/pdfs/2011-123.pdf

[8] Central Statistical Office. Labour force survey in Poland. Warsaw 2014. Web site: http://stat.gov.pl/cps/rde/xbcr/ gus/PW_aktyw_ekonom_ludn_3kw_2013.pdf

[9] Central Statistical Office. Polish population forecasts for the years 2008-2035. Warsaw 2007. Web site: http://stat. gov.pl/cps/rde/xbcr/gus/L_prognoza_ludnosci_Pl_20082035.pdf

[10] Chang W.R., Courtney T. K., Grongvist R., Redfern M. (2002) Measuring slipperiness: Human locomotion and surface factors. CRC Press

[11] Chang W.R., Grönqvist R., Leclercq S., Myung R., Makkonen L., Strandberg L., Brungraber R. J., Mattke U., Thorpe S. C. (2001). The role of friction in the measurement of slipperiness, Part 1: Friction mechanisms and definition of test conditions. Ergonomics, 44(13), 1217-1232.

[12] Chen S., Jin J., Lou E. (2013). Toward Slip and Fall Prevention: Exploring the Guidance and Challenges of Anti-slip Footwear. Procedia Engineering 43, 364-368

[13] Council Directive 89/686/EWG on personal protective equipment

[14. Gao C., Holmer I., Abeysekera J. (2008). Slips and falls in a cold climate: Underfoot surface, footwear design and worker preferences for preventive measures. Applied Ergonomics, 39, 385-391

[15] Grönqvist R. (1995). Mechanisms of friction and assessment of slip resistance of new and used footwear soles on contaminated floors. Ergonomics, 28, 224-241;

[16] Gronqvist R., Hirvonen M., Rajamaki E., Matz S.(2003). The validity and reliability of a portable slip meter for determining floor slipperiness during simulated heel strike. Accident analysis and prevention, 35(2), 211-225

[17] Gronqvist R. (Kumar S.). 1999. Slips and falls.
Biomechanics in Ergonomics. Taylor\&Francis (London)

[18] Gronqvist R., Chang W.R., Courtney T.K., Leamon T.B., Redfern M., Strandberg L. (2001). Measurement of slipperiness: fundamental, concepts and definitions. Ergonomics, 44, 1102-1117

[19] Heshmat H., Godet M. Berthier Y. (1995). On the role and mechanism of dry triboparticulate lubrication. Society of Tribologists and Lubrication Engineering, 51, 557-564

[20] Irzmańska E. (2014). Footwear use at workplace and recommendations for the improvement of its functionality and hygiene. AUTEX Research Journal, 14(2), 1-6

[21] Koepsell T. D., Wolf M. E., Buchner D. M., Kukull W. A., LaCroix A. Z., Tencer A. F., Frankenfeld C. L., Tautvydas M., Larson E. B.(2004). Footwear style and risk of falls in older adults, Journal of the American Geriatrics Society, 52(9), 14945-1501

[22] Kong P.W., Suyama J., Hostler D. (2013). A review of risk factors of accidental slips, trips and falls among firefighters. Safety Science, 60, 203-209

[23] Kostka T., Furgal W., Gawroński W., Bugajski A., Czamara A., Klukowski K., Krysztofiak H., Lewicki R., Szyguła Z., Tomaszewski W., Trzaska T., Widuchowski J., Ziemba A., Jegier A. (2012). Recommendations of the Polish Society of Sports Medicine on age criteria while qualifying children and youth for participation in various sports. British Journal of Sports Medicine, 46(3), 159-16

[24] Leclerq S., Tisserand M. Saulnier H. (1995). Tribological concepts involved in slipping accident analysis. Ergonomics, 38, 197-208

[25] Lockhart T. E., Smith J. L., Woldstad J. C. (2005). Effects of Aging on the Biomechanics of Slips and Falls. Human Factors, 47(4), 708-729

[26] Lord S.R., Bashford G.M. (1996). Shoe characteristics and balance in older women. Journal of the American Geriatrics Society, 44, 429 - 433

[27] Lord S.R., Bashford G.M., Howland A., Munroe B.J. (1999). Effects of shoe collar height and sole hardness on balance in older women. Journal of the American Geriatrics Society, 47(6), 681-684

[28] Manning D.P., Ayers I., Jones C., Bruce M., Cohen K. (1988). The incidence of underfoot accidents during 1985 in a working population of 10,000 Merseyside people. Journal of Occupational Accidents, 10, 121-130

[29] Manning D.P., Mitchell R.G., Blanchfield L.P. (1984). Body movements and events contributing to accidental and nonaccidental back injuries. Spine, 9, 734-739

[30] Menant J.C., Steele J.R., Menz H.B., Munro B.J., Lord S.R. (2008). Optimizing footwear for older people at risk of falls. Journal of Rehabilitation Research and Development 45(8), 1167-8135

[31] Menz H.B., Lord S.R. (2001). Foot pain impairs balance and functional ability in community-dwelling older people. Journal of the American Podiatric Medical Association, 91(5), 222-229

[32] Menz H.B., Lord S. T., Mclntosh A.S. (2001). Slip resistance of casual footwear: implications for falls in older adults. Gerontology, 47(3), 145-149

[33] Moore D.F. (Raynor G. V.) (1972). The friction and lubrication of elastomers. In: International series of monographs on material science and technology. Vol. 9. Pergamon Press (Oxford) 
[34] Nagata H., Watanabe H., Inoue Y., Kim I.J. (2009). Fall and validities of various methods to measure frictional properties of slippery floors covered with soapsuds. Proceedings of the 17th world Congress on Ergonomics 2009

[35]Preston J.W. (2007). Safety Engineering Services. Retrivered 11.05.2014 http://www.safetybiz.com/Sliptest. htm

[36] Protector T.D. Coleman V. (1988). Slipping, tripping and falling accidents in Great Britain - present and future. Journal of Occupational Accidents, 9, 269-285

[37] Qu X. (2014). Impacts of different types of insoles on postural stability in older adults. Applied Ergonomics A, 46, 38-43

[38] Qui F., Cole M.H., Davids K.W., Henning E.M., Silburn P.A., Netscher H., Kerr G.K. (2012). Enhanced somatosensory information decreases postural sway in older people. Gait Posture, 35, 630-635

[39] Redfern M.S., Marcotte A., Chaffin D.B. (1990). A dynamic coefficient of friction measurement device for shoe/floor interface testing. Journal of Safety Research, 21, 61-65

[40] Robbins S., Waked E., McClaran J. (1995). Proprioception and Stability: Foot Position Awareness as a Function of Age and Footware. Age Ageing, 24 (1), 67-72

[41] Standard Test Method for Determining the Static Coefficient of Friction of Ceramic Tile and Other Like Surfaces by the
Horizontal Dynamometer Pull-Meter Method (Withdrawn 2014) http://www.astm.org/Standards/C1028.htm

[42] Standard Test Method for Using a Horizontal Pull Slipmeter (HPS) http://www.astm.org/Standards/F609.htm

[43] Strandberg L. (1985). The effect of conditions underfoot on falling and overexertion accidents, Ergonomics, 28, 131147

[44] Su K., Ling S.M., Winters J., Ferrucci L. (2009). Agerelated mechanical work expenditure during normal walking: The Baltimore longitudinal study of aging. Journal of Biomechanics, 45(12), 1834-1839

[45] Tisserand M. (1985). Progress in the prevention of falls caused by slipping, Ergonomics, 28(7), 1027-1042

[46] Twardowska-Rajewska, J. (2006). Krótki program usprawniania seniorów w celu minimalizowania zaburzeń równowagi. Doniesienie wstępne. Gerontologia Polska, 14 (1), 41-45.

[47] Yamaguchi T., Umetsu T., Ishizuka Y., Kasuga K., Ito T., Ishizawa S., Hokkirigawa K. (2012). Development of new footwear sole surface pattern for prevention of slip-related falls. Safety Science, 50, 986-99

[48] Yang F., Espy D., Bhatt T., Pai Y.C. (2012). Two types of slip-induced falls among community dwelling older adults. Journal of Biomechanics, 45, 1259-1264 